www.jmscr.igmpublication.org

Index Copernicus Value: 79.54

ISSN (e)-2347-176x ISSN (p) 2455-0450

crossref DOI: https://dx.doi.org/10.18535/jmscr/v7i6.87

\title{
Follow up of Patients With Severe Allergic Asthma on one year Anti-IgE (Omalizumab) Therapy
}

\author{
Authors \\ Brig Sarvinder Singh ${ }^{1}$, Lt Col Santosh Kumar Singh*², Lt Col Tentu Ajai Kumar ${ }^{3}$ \\ ${ }^{1}$ Commandant, Military Hospital, Gwalior, Madhya Pradesh, India \\ ${ }^{2}$ Classified Specialist in Internal Medicine, Command Hospital, Uddhampur, Jammu and Kashmir, India \\ ${ }^{3}$ Classified Specialist in Pulmonary Medicine, Military Hospital Namkum, Ranchi, Jharkhand \\ *Corresponding Author \\ Lt Col Santosh Kumar Singh
}

\begin{abstract}
Introduction: Atopic patients with severe asthma frequently have poorly controlled disease despite intensive treatment. These patients are frequently treated with oral corticosteroids which can results in serious sideeffects. Anti-IgE antibody had been used in severe persistent allergic asthma. However, its long-term efficacy in patients in India has not been reported.

Aim: Anti-IgE antibody had been used in severe persistent allergic asthma in adults. Here we are presentating our experience of 30 patients with 52 weeks of Anti IgE Therapy follow-up.

Method and Materials: 30 (16 male and 14 female) patients, with mean age of 49 having severe persistent allergic asthma with recurrent exacerbations and having oral/ IV/ high dose ICS (Inhaled Corticosteroids) who received Omalizumab 300mg once a month for 6 month to 1 year were included in the study. Total dose of oral Steroids, use of rescue medications, changes in lung function ( FEV1) and ICS dose were recorded at the baseline, 16 weeks and at 52 weeks.

Results: There was significant reduction in use of oral steroid at 16 week and 52 weeks $-10.5 \mathrm{mg}$ and $22.5 \mathrm{mg}$ respectively. Use of rescue medications decreased by -7.90 puffs ( $p-<0.001)$ at 16 weeks and by -13.67 puffs $(p-<0.001)$ at 52 weeks. Improvements in lung Function ( FEV1) observed was $700 \mathrm{ml}$ from Base Line after 52 weeks therapy. ACT Score showed significant improvement at 16 wks and at 52 wks.

Conclusion: Use of anti-IgE antibody for 1 year led to significant improvement in patients with severe persistent allergic asthma.

Keywords: Allergic asthma, Asthma Control Test, Immunoglobulin E levels, Omalizumab, Oral Corticosteroids use
\end{abstract}

\section{Introduction}

Asthma is a major public health problem which is under diagnosed and under managed because of poor symptom perception by the patients and even poorer understanding by the treating physician. A large population has a refractory disease even after an optimal therapy with ICS and long-acting b2agonists (LABA). OCS (oral corticosteroids) are frequently used to treat severe asthma/ acute exacerbation in short course and frequently maintenance OCS are used to achieve control in these patients. ${ }^{[1]}$ The long-term use of OCS is associated with significant side effects like cataracts, 
flare-up of latent diabetes, hypertension, osteoporosis and weight gain. ${ }^{[2]}$

Omalizumab is a recombinant humanized monoclonal antibody that selectively binds to human IgE. This prevents the interaction of $\operatorname{IgE}$ to the high-affinity receptors on basophils and mast cells, thus interrupting the inflammatory cascade involved in the pathogenesis of allergic asthma. Several studies have demonstrated the therapeutic efficacy and safety of omalizumab in asthmatic patients. They found clinically significant reduction in asthma exacerbations, use of oral corticosteroids, emergency department (ED) visits, and asthma control. ${ }^{[1,3,4,5]}$

Anti IgE therapy has been incorporated into the current guidelines for the treatment of asthma. Current GINA (Global Initiative against Asthma) guidelines recommend use of omalizumab as a step 5 treatment, in patients who remain symptomatic despite optimum treatment ${ }^{6}$. The purpose of this study was to investigate the clinical effects of omalizumab in patients with severe persistent allergic asthma in our setup.

\section{Methods}

This was a single centre 52-week observational study conducted at a tertiary care respiratory centre. The objective of the study was to evaluate the efficacy of omalizumab in cases of uncontrolled severe allergic asthma inspite of optimal therapy for asthma and who were on high dose ICS or oral corticosteroids.

Patients: The patients of severe allergic asthma attending resipratory OPD, who were enrolled for omiluzumab therapy and meeting the inclusion criterion were included in the study. Omalizumab was administered at a dose of $300 \mathrm{mg}$ monthly S/C in our study.

Inclusion criteria was a clinical diagnosis of severe asthma with positive allergy test results for at least 1 perennial aeroallergen. Patients with IgE level of 30 to $1500 \mathrm{IU} / \mathrm{ml}$ and having regular/occasional requirement of systemic steroid treatment (IV or oral) or high dose of ICS were included. Patients having frequent exacerbations requiring frequent emergency department visit/ hospitalization/ short course of oral steroids were also included.

Assessments: Data on the following parameters were collected at Baseline (prior to commencing omalizumab therapy), 16 weeks and 52 weeks after initiation of Omalizumab therapy:

OCS dose

ACT (Asthma Control Test) score

Use of rescue medication, short acting beta 2 agonists and

Lung function $\left(\mathrm{FEV}_{1}\right)$

Change in ICS (Inhaled Coticosteroids) dose, LABA dose, and status of asthma control (mild, moderate, or severe) were also recorded.

\section{ACT}

It is a validated score to assess control of asthma in patients of 12 years and above. ACT uses five questions related to asthma symptoms over last 4 weeks and scores them from scale of one to five from poorly contolled to the well controlled symptoms. ACT assesses the effect on daily functioning, shortness of breath, nocturnal symptoms, frequency of use of rescue medication and self assessment of asthma control in last 4 weeks.Total scores range from 5 to 25 and with higher scores reflecting greater asthma control. An ACT score $>19$ indicates well-controlled asthma.

Asthma control clinically is recorded as mild, moderate and severe based on asthma symptoms. Daytime symptoms more than twice/week, any night time awakening due to asthma symptom, use of rescue medication more than twice/week or any limitation of activity due to asthma in past 4 weeks are given one point each. Asthma is well controlled if score is zero, 1-2 score is partly controlled and score of 3-4 is uncontrolled asthma.

Analysis: Summary statistics describing change from baseline in OCS dose, ACT score, rescue medication use and change in $\mathrm{FEV}_{1}$ were calculated for all patients receiving omalizumab at 16 weeks and at 52 weeks.

Limitations: In this study the exact pre and post effects of omalizumab were not included. However the efficacy of the drug (the steroid sparing effect) was calculated with the help of $\mathrm{p}$-value. 


\section{Results}

\section{Patient demography and baseline characteristics}

A total of 30 patients (53.3\% male, $46.7 \%$ female) who were on regular followup and receiving omalizumab from Respiratory OPD were included in this study. Total $70 \%$ of the patients had severe asthma (uncontrolled) and $30 \%$ had moderate (partially controlled) asthma on optimization of therapy with ICS and LABA. Patients with mild (well-controlled) asthma were not included in the study. The key baseline characateristics are listed in the below

\section{Table: No 1}

\begin{tabular}{|c|c|}
\hline Variable & Patients $(n=30)$ \\
\hline Mean age, years (SD) & 53.3 \\
\hline Female, $\mathrm{n}(\%)$ & $46.7 \%$ \\
\hline Mean duration of allergic asthma, years (SD) & 28.6 years \\
\hline RAST for perennial aeroallergens, $n(\%)$ & $95.6 \%$ \\
\hline History of seasonal allergy, $\mathrm{n}(\%)$ & $67.3 \%$ \\
\hline \multicolumn{2}{|l|}{ Smoking history, n (\%) } \\
\hline Never smoked & $78.6 \%$ \\
\hline Ex-smoker & $15.8 \%$ \\
\hline Current smoker & $5.6 \%$ \\
\hline \multicolumn{2}{|c|}{ Asthma control/severity (investigator assessment), $n$ (\%) } \\
\hline Controlled & 0 \\
\hline Partly controlled/Moderate & $30 \%$ (9 patients) \\
\hline Uncontrolled/severe & $70 \%$ (21 patients) \\
\hline
\end{tabular}

\section{OCS use}

The most commonly used OCS was prednisolone. The mean total daily OCS dose reduction at 16 week and at 52 weeks from Baseline was $10.5 \mathrm{mg}$ and $22.5 \mathrm{mg}$ respectively. The number of patients receiving OCS was lower at Week $16(40 \%)$ and week $52(23.3 \%)$ than at baseline $(56.6 \%)$

\section{ACT score}

There was a significant Improvement in ACT scores at week 16 (score 17.1 vs. 11.3 at baseline) and week 52 (20.8 vs 11.3 at baseline)

\section{Rescue medication use}

The use of rescue medications, short acting beta2 agonists, decreased by 7.90 puffs $(\mathrm{p}<0.001)$ at 16 weeks and by 13.67 puffs $(\mathrm{p}<0.001)$ at 52 weeks from baseline.

\section{Lung fuction}

The lung function on spirometry were improved significantly at 52 weeks compared to baseline (change in $\mathrm{FEV}_{1}=700 \mathrm{ml}$ ).

\section{Other parameters}

The change in ICS dose and LABA dose are shown in below Table: No 2

Table no 2 The mean change in ICS dose and LABA dose at 16 weeks and 52 weeks

\begin{tabular}{|l|c|c|}
\hline Parameter & $\begin{array}{c}\text { Mean change from } \\
\text { Baseline at 16 weeks }\end{array}$ & $\begin{array}{c}\text { Mean change from } \\
\text { Baseline at 52 weeks }\end{array}$ \\
\hline ICS dose & $-287.50 \mathrm{mg}(p<.001)$ & $-458.33 \mathrm{mg}(p<.05)$ \\
\hline LABA dose & $-26.25(p<.001)$ & $-58.33(p<.001)$ \\
\hline
\end{tabular}

The comparison of asthma severity between baseline and week 52 is shown in below Table: No 3

Table no 3 Comparison of asthma severity between baseline and at 52 weeks

\begin{tabular}{|l|c|c|}
\hline Asthma severity & Baseline & Week 52 \\
\hline Mild & $0 \%$ & $33.3 \%$ \\
\hline Moderate & $30 \%$ & $66.6 \%$ \\
\hline Severe & $70 \%$ & $0 \%$ \\
\hline
\end{tabular}

\section{Discussion}

In this study there was significant reduction in use of maintenance OCS in patients of uncontrolled and severe persistant allergic bronchial asthma who were treated with omalizumab $300 \mathrm{mg}$ S/C monthly. There was significant reduction in mean dose of OCS (10.5mg and $22.5 \mathrm{mg}$ at 16 and 52 weeks respectively). The no of patients using maintenance OCS also decreased. These findings were consistent with study conducted by Molimard M et.al. ${ }^{[7]}$

The patients enrolled in the study also showed significantly improved lung function (FEV1). There was a significant reduction in daily use of rescue medication use. The maintenace dose of ICS and LABA were also reduced significantly in this study, which suggested an improvement in asthma control. This is again confirmed by improvement in of asthma severity analysis after 52 weeks, there was no patients classified uncontrolled asthma. Our findings are consistent with those of other real-life studies of omalizumab in various parts of the world. Several recent publications have shown role of omalizumab as an add-on treatment to high dose inhaled corticosteroids and inhaled long-acting $\beta 2$ agonist bronchodilators in severe allergic asthma . 3429patients of moderate to severe allergic bronchial asthma patients who were having high 
IgE levels and were on high dose of ICS and LABA were analysed in various randomized control trial in 2011. ${ }^{[8,9]}$ Augmenting the treatment of asthma with omalizumab resulted in a significant number of patients to reduce the dose of inhaled corticosteroids. There was significant reduction in the risk of asthma exacerbations/ ED visits. ${ }^{[10]}$

In a randomized controlled trial Hanania NA et al studied 850 patients who had poorly controlled symptoms on high dose inhaled corticosteroids ( $\geq 1000 \mathrm{mcg}$ of fluticasone) and inhaled long-acting $\beta 2$ agonist bronchodilators and were treated with omallizumab for 48 weeks. ${ }^{[11]}$ They reported $25 \%$ reduction in the rate of asthma exacerbations at 48 week of omalizumab use. This study also showed good clinical response on addition of omalizumab to patients with poorly controlled asthma inspite of optimal treatment with high dose inhaled corticosteroids and inhaled long-acting $\beta 2$ agonist bronchodilators

Many studies like in France ${ }^{[12]}$, Germany ${ }^{[13]}$, Belgium $^{[14]}$, United Kingdom ${ }^{[15]}$ and other countries have reported their experience with omalizumab treatment in patients of allergic asthma. The results of these studies suggest that omalizumab is an effective add on treatment for patients with poorly controlled allergic asthma and our observation study has show similar outcomes.

The major adverse effect associated with the use of omalizumab is anaphylaxis. There has been concerns about increase in rate of malignancies, cardiovascular and cerebrovascular events. The incidence of anaphylaxis reported in clinical trials is $0.14 \%$ in omalizumab treated patients and $0.07 \%$ in control patients. ${ }^{[16]}$ There was no major side effect seen in our study group however incidence of maligancies can not be commented upon in such a short perion of observation, long term follow up studies will be required fo this.

\section{Conclusions}

Our study has shown that addition of omalizumab in treatment of uncontrolled persistent allergic asthma on regular therapy is associated with steroid sparing effect and it also lead to better control of asthma symptoms (ACT). Omalizumab is effective in improving lung function (FEV1). It reduces the frequency of use ofrescue medication (SABA) and reduces the requirement of ICS and LABA. The long term use of oral corticosteroids is associated many side effects as mentioned above hence a therapy which permits to reduce dose of steroids, oral or inhaled is an important addition to the treatment of asthma.

\section{Acknowledgement}

The authors thank all the faculty and technical staff of Department of Pulmonary Medicine, Internal Medicine and Laboratory Medicine for their constant support during the study.

\section{References}

1. M. Humbert, R. Beasley, J. Ayres, R. Slavin, J. Hebert, J. Bousquet, et al.

Benefits of omalizumab as add-on therapy in patients with severe persistent asthma who are inadequately controlled despite best available therapy (GINA 2002 step 4 treatment): INNOVATE. Allergy, 60 (2005), pp. 309-316

2. J.R. Curtis, A.O. Westfall, J. Allison, J.W. Bijlsma, A. Freeman, V. George, et al. Population-based assessment of adverse events associated with long-term glucocorticoid use. Arthritis Rheum, 55 (2006), pp. 420-426

3. Hanania NA, Alpan O, Hamilos DL, Condemi JJ, Reyes-Rivera I, Zhu J, Rosen $\mathrm{KE}$, Eisner MD, Wong DA, Busse W: Omalizumab in severe allergic asthma inadequately controlled with standard therapy: a randomized trial. Ann Intern Med. 2011, 154: 573-582.

4. Omalizumab (xolair) prescribing information. Available at: http://www.emea.europa.eu/humandocs/PDF s/EPAR/Xolair/emea-combined-h606en.pdf

5. G. D'Amato. Role of anti-IgE monoclonal antibody (omalizumab) in the treatment of bronchial asthma and allergic respiratory 
diseases. Eur J Pharmacol, 533 (2006), pp. 302-307

6. GINA Guideline 2016

7. Molimard M, Buhl R, Niven R, Le Gros V, Thielen A, Thirlwell J, Maykut R, Peachey $\mathrm{G}$ : Omalizumab reduces oral corticosteroid use in patients with severe allergic asthma: real-life data. Respir Med. 2010, 104: 13811385.

8. Lanier B, Bridges T, Kulus M, Taylor AF, Berhane I, Vidaurre CF. Omalizumab for the treatment of exacerbations in children with inadequately controlled allergic (IgEmediated) asthma. J Allergy Clin Immunol. 2009;124(6):1210-6.

9. Ohta K, Miyamoto $\mathrm{T}$, Amagasaki $\mathrm{T}$, Yamamoto $M$ on behalf of the Study $G$. Efficacy and safety of omalizumab in an Asian population with moderate-to- severe persistent asthma. Respirology. 2009;14(8):1156-65.

10. Rodrigo GJ, Neffen H, Castro-Rodriguez J. Efficacy and safety of subcutaneous omalizumab vs. placebo as add-on therapy to corticosteroids for children and adults with asthma. Chest. 2011;139(1):28-35.

11. Hanania NA, Alpan O, Hamilos DL, Condemi JJ, Reyes-Rivera I, Zhu J, et al. Omalizumab in Severe Allergic Asthma Inadequately Controlled With Standard Therapy. Ann Intern Med. 2011;154(9):57382.

12. Molimard M, Gros VL. Impact of PatientRelated Factors on Asthma Control. J Asthma. 2008;45(2):109-13.

13. Korn S, Thielen A, Seyfried S, Taube C, Kornmann O, Buhl R. Omalizumab in patients with severe persistent allergic asthma in a real-life setting in Germany Resp Med. 2009;103(11):1725-31.

14. Brusselle G, Michils A, Louis R, Dupont L, Van de Maele B, Delobbe A, et al. 'Real-life' effectiveness of omalizumab in patients with severe persistent allergic asthma: The
PERSIST study. Resp Med. 2009; 103(11):1633-42.

15. Niven R, Chung KF, Panahloo Z, Blogg M, Ayre G. Effectiveness of omalizumab in patients with inadequately controlled severe persistent allergic asthma: An open-label study. Resp Med. 2008;102(10):1371-8.

16. Corren J, Casale TB, Lanier B, Buhl R, Holgate S, Jimenez P. Safety and tolerability of omalizumab. Clin Exp Allergy. 2009;39(6):788-97. 